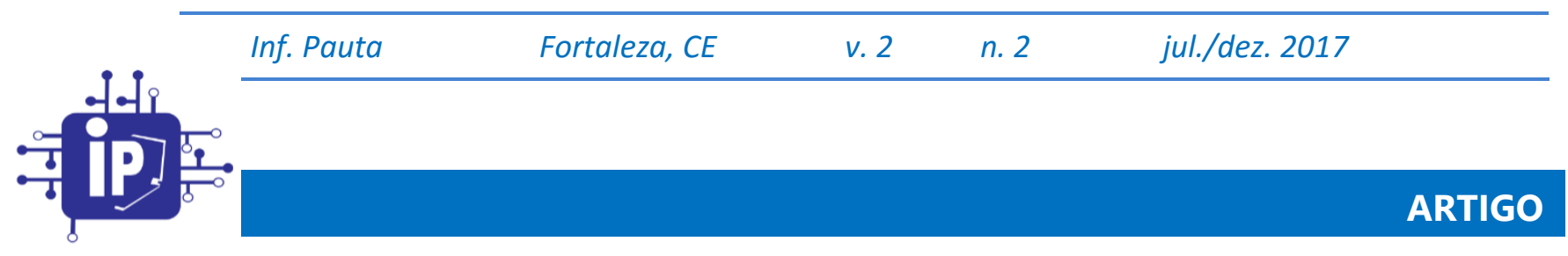

\title{
ENTRE O OBJETO E O SUJEITO: COMPOSIÇÃO, DIÁLOGO E CONFLUÊNCIA NA RECUPERAÇÃO DA INFORMAÇÃ̃̃ EM ARQUIVOS
}

\author{
BETWEEN THE OBJECT AND THE SUBJECT: COMPOSITION, DIALOGUE \\ AND CONFLUENCE IN THE RETRIEVAL OF INFORMATION IN ARCHIVES
}

\author{
Dacles Vágner da Silva \\ UFC \\ Osvaldo de Souza \\ UFC \\ Jefferson Veras Nunes \\ UFC \\ Lidia Eugenia Cavalcante \\ UFC
}

\section{RESUMO}

A Recuperação da Informação (RI) é investigada em diversas áreas, dentre elas a Arquivologia. Ao examinar o conceito de RI no campo da Arquivologia, percebe-se a influência de estudiosos e teóricos da Ciência da Informação (CI) e da Ciência da Computação. No presente texto busca-se entender a RI em relação aos ambientes chamados de arquivo e entender como a RI foi exercitada em publicações dos últimos anos sob a égide de elementos que podem compor visões de natureza tanto objetivista, bem como subjetivista - típicas de uma discussão já em desenvolvimento no terreno epistemológico da CI. A partir de tais traçados, lança-se o problema de pesquisa: como se relacionam as questões e os elementos tanto de ordem da objetividade como da subjetividade referentes à RI e aos temas correlatos no campo arquivístico? A pesquisa teve abordagem qualitativa, baseada em levantamento bibliográfico. A coleta foi empreendida em portais digitais de revistas e periódicos científicos da CI e Arquivologia. Coletaram-se estudos que tratavam da RI em arquivos nos últimos cinco anos. 0 método de análise dos dados utilizado foi de conteúdo. Achados da pesquisa indicam que as visões baseadas na objetividade e subjetividade, considerando-se a relação objeto-sujeito, não se apresentam dicotômicas.

Palavras-chave: Recuperação da Informação. Arquivologia. Objetividade-subjetividade. Ciência da Informação.

\begin{abstract}
Information retrieval (IR) is investigated in several areas, among them Archival Science. When examining the concept of IR in the field of archival science, one can see the influence of theorists from Information Science (IS) and Computer Science. This paper focus to understand IR in relation to the so-called archival environments and to understand how IR has been exercised in publications of recent years under the aegis of elements that can compose visions of both objectivist and subjectivist natures - typical of a discussion already under development in the epistemological field of IS. From these traces we raised the problem: how are the issues and elements related both to the order of objectivity and to the subjectivity of IR and related issues in the archival field related? The research had a qualitative approach, based on a bibliographical survey. Collecting data was performed in digital portals of scientific journals and journals of related to Archival Science. We collected studies that deal with IR in archives in the last 5 years. The data analysis method used was content analysis. Findings of the research indicate that visions based on objectivity and subjectivity, considering the object-subject relationship, are not dichotomous.
\end{abstract}

Keywords: Information retrieval. Archivology. Objectivity-subjectivity. Information Science. 


\section{INTRODUÇÃO}

A Recuperação da Informação (RI), no contexto de frequente dinamicidade tecnológica e grande produção de dados/informações, é evidenciada como objeto crucial na Arquivologia, na Ciência da Informação (CI) e em áreas correlatas, como a Ciência da Computação (CC). Com o uso intenso de tecnologias digitais de informação e comunicação (TDIC) no cotidiano das organizações, verifica-se que a questão da recuperação é cada vez mais influente para operações de ordem administrativa. Todo esse contexto de contínua e intensa produção de documentos, aliado aos desafios que vão sendo postos às disciplinas documentais, como a Arquivologia e áreas afins (ARAÚJO, 2014), tais como a $\mathrm{CI}$, estabelece problemáticas que se examinam tanto por estudiosos de uma como da outra área.

Nesse sentido, a discussão que emana do próprio objeto da área - a informação invariavelmente envolve temáticas que, direta ou indiretamente, relacionam-se com esse objeto, no caso em particular considerado neste texto, a recuperação da informação.

Ao se discutir a RI no contexto da CI, torna-se também evidente a necessidade de discussão sobre a informação como algo externo, em certo antagonismo a informação como construção mental do indivíduo. Sobre o uso da informação, concordamos com Varela e Barbosa (2016), que nos dizem:

Do ponto de vista objetivo, no âmbito das práticas informacionais e de sua interlocução com as Ciências Cognitivas, depreende-se que a busca e o uso da informação, em todas as dimensões - acesso, análise, interpretação, avaliação, produção, entre outros -, subentende o domínio de competências e habilidades específicas e inerentes, bem como o domínio da leitura e seu significado crítico, sendo todas estas categorias mentais integrantes da ação cognitiva.

Sendo a busca e uso da informação pertencentes às categorias mentais, há que se inferir serem, portanto, construções mentais e, portanto, não externas ao indivíduo. Todavia, a discussão sobre a informação como objeto no mundo externo ou como construção na mente de indivíduos (ZINS, 2011) corrobora para, sob uma perspectiva pluridisciplinar (POMBO, 2008), ampliar o leque de discussões sobre a RI em outras áreas. Ao incorrer a um exame do conceito de RI no campo da Arquivologia, percebe-se que a mesma vivenciou influências de estudiosos e teóricos da CI. É necessário, também, formular o sentido de recuperação da informação, no presente estudo, como sinônimo também de recuperação de documentos. 
Portanto, é essencial compreender sobre a RI, no que tange aos ambientes denominados de arquivo, e entender como o conceito de RI foi trabalhado em publicações dos últimos anos sob a égide de elementos que podem compor visões de natureza tanto objetivista como subjetivista - típicas de uma discussão já em desenvolvimento no terreno epistemológico da CI. A partir de tais caminhos, pode-se indagar: como se relacionam as questões e os elementos tanto de ordem da objetividade, bem como da subjetividade referentes à RI e aos temas correlatos no campo arquivístico? Elege-se como objetivo no presente trabalho, portanto, conhecer e discutir as relações entre a objetividade e a subjetividade no contexto da RI no campo arquivístico.

0 trabalho se divide em: "1 INTRODUÇÃO", que contextualiza e inicia a discussão do estudo no campo da RI, corroborado no ambiente de arquivos; "2 RECUPERAÇÃO DA INFORMAÇÃO: conceito", que expõe o entendimento do conceito de RI pelas duas principais áreas que o investigam, a saber a Ciência da Computação e a CI; "3 A OBJETIVIDADE E A SUBJETIVIDADE NO CONTEXTO DA CIÊNCIA", onde analisou-se, de maneira sucinta, como a ciência entende o posicionamento do sujeito e também do objeto como partícipe na construção do conhecimento; “4 PERCURSO METODOLÓGICO”, onde se explicitou os procedimentos e método utilizados para compor a investigação científica do estudo; “5 A RECUPERAÇÃO DA INFORMAÇÃO EM ARQUIVOS: análise de estudos”, que trouxe a exposição dos dados coletados, bem como a análise dos mesmos; "6 CONSIDERAÇÕES FINAIS", que finalizou a discussão, suscitando complementos para a análise do estudo e reflexões sobre a investigação efetuada; e "REFERÊNCIAS", expondo os trabalhos que colaboraram para a fundamentação e objetivo do presente trabalho.

\section{RECUPERAÇÃO DA INFORMAÇÃO: conceito}

0 processo de industrialização traz consigo todo um arsenal de meios para produção de dados, informação e consequente conhecimento. Desde a invenção da prensa por Gutenberg, do telefone por Antonio Meucci e Alexander Graham Bell e da revolução tecnológica, que inseriu dispositivos cada vez menores e significativos ao cotidiano social - a exemplo do microcomputador e o celular -, o homem passa cada vez mais a produzir informação e passa também a ser consumidor dela.

Ainda que a etapa de produzir informação seja intuitivamente corriqueira, é no procedimento de recuperar o que foi produzido que as entidades (indivíduos e 
organizações) suprem também suas necessidades informacionais. Sendo uma proeminente área de investigação científica, é importante ressaltar que o campo da RI é responsável por desenvolver e investigar questões que vão desde a ordem teórica, até a ordem prática, como a medição de índices de revocação, precisão e sucesso nos procedimentos de busca e recuperação, aprimoramento e constituição de algoritmos para sistemas de RI, dentre outras questões. Ela surge, portanto, como área que incentiva o desenvolvimento de produtos e a resolução de problemas comuns às áreas, fato que evidencia a sua base epistemológica, multidisciplinar, no objeto informação.

É nesse entrelaçamento multidisciplinar que a RI é conceituada, segundo BaezaYates e Ribeiro-Neto (2013, p. 1), como temática que "trata da representação, armazenamento, organização e acesso a itens de informação, como documentos, páginas Web, catálogos online, registros estruturados e semiestruturados, objetos multimídia, etc." Infere-se, pela visão dos autores, que a RI é encontrada em diversas áreas de aplicação, abrangendo desde sistemas documentais até sistemas web de funcionalidades diversas.

Cardoso (2004, p. 1) ressalta o viés de automação do processo, afirmando que a RI estuda "o armazenamento e recuperação automática de documentos, que são objetos de dados, geralmente textos", enfatizando componentes e funcionamento de um sistema de RI:

Os componentes do sistema incluem documentos, necessidades do usuário, gera a consulta formulada, e finalmente o processo de recuperação que, a partir das estruturas de dados e da consulta formulada, recupera uma lista de documentos considerados relevantes (CARDOSO, 2004, p. 2).

As necessidades do usuário citadas por Cardoso (2004) não são necessariamente uma abordagem, segundo Baeza-Yates e Ribeiro-Neto (2013), focada pela Ciência da Computação. Para estes, o enfoque dado ao usuário é uma perspectiva dada muito mais pela Ciência da Informação. Corroborando essa perspectiva, Garcia (2007, p. 1) enfatiza que

Para as áreas que lidam com a informação, o sentido é outro, pois para se recuperá-la, há que se selecionar, armazenar, preservar, tratar por um sistema, para permitir que o desejo sentido ou latente do usuário seja atendido, avizinhando-nos a um sentido diverso de perdido.

Peter Ingwersen, no livro "Information Retrieval Interaction", ressalta o usuário como partícipe do processo aqui discutido. Na visão do autor: 
“A recuperação da informação está preocupada com os processos envolvidos na representação, armazenamento, pesquisa e busca de informações relevantes para um requisito de informação desejado por um usuário humano" i (INGWERSEN, 1992, p. 49, tradução nossa).

Com a apresentação de definições e conceituações por autores provenientes tanto da área da CC como pela CI, podemos recorrer ao estudo desenvolvido por Khapre e Basha (2012). Na visão dos autores, “A partir da definição das duas disciplinas de recuperação de informações, é fácil ver que as duas compartilham uma perspectiva comum de recuperação de informações - usuários, tecnologia da informação e direções de pesquisa”ii (KHAPRE; BASHA, 2012, p. 232). Ainda sobre o entendimento da CC sobre a RI, e consequentemente do elemento denominado "informação", Khapre e Basha (2012, p. 235) entendem que

[...] pesquisadores de recuperação de informações geralmente tratam a informação como fato e usam informações para fazer algum trabalho, como um índice de informação, codificação de informações, decomposição e análise de informações. Essa visão é baseada na natureza da informação, ou seja, específica, definível e pode ser codificada. A Recuperação da Informação da Ciência da Computação segue o princípio racional e tradicional de que a informação é a existência factual do mundo externo das coisas.iii (tradução nossa).

Na perspectiva da CI, segundo autores como Capurro, Khapre e Basha, discutidos a seguir, faz-se alusão aos paradigmas físico, cognitivo e social para entendimento do conceito de "informação". Nesse viés de análise, Khapre e Basha (2012, p. 233) são enfáticos ao afirmarem que "no campo da CI, a RI aceitou basicamente a natureza multinível do conceito de informação”iv. De acordo com a visão de Capurro (2003), é possível analisar como a RI foi influenciada por cada um dos paradigmas citados anteriormente. No caso do paradigma físico, o autor cita, por exemplo, os experimentos de Cranfield e corrobora à sua visão o lugar do sujeito (usuário) no processo.

Torna-se evidente que, no campo da ciência da informação, o que esse paradigma exclui é nada menos que o papel ativo do sujeito cognoscente ou, de forma mais concreta, do usuário, no processo de recuperação da informação científica, em particular, bem como em todo processo informativo e comunicativo, em geral. (CAPURRO, 2003, não paginado).

Quanto ao paradigma cognitivo, proposto por Bertram C. Brookes e influenciado pela ontologia e epistemologia de Karl Popper, Capurro (2003, não paginado) afirma que "Brookes subjetiva, por assim dizer, esse modelo no qual os conteúdos intelectuais 
formam uma espécie de rede que existe somente em espaços cognitivos ou mentais, e chama tais conteúdos de 'informação objetiva'” e que a partir de influências, principalmente de Nicholas Belkin,

A teoria dos modelos mentais tem tido impacto no estudo e na concepção de sistemas de recuperação da informação, como mostram as análises empíricas realizadas por Pertti Vakkari com relação à conexão entre estado anômalo do conhecimento e estratégias de busca (Vakkari 2003) (CAPURRO, 2003, não paginado).

E quanto ao paradigma social, Frohmann (1995 apud Capurro, 2003) alerta quanto ao seu caráter "associal" e idealista. 0 paradigma social leva em conta a tessitura social onde o indivíduo se situa e não descarta o viés cognitivo. Capurro (2003, não paginado) não deixa de citar, ao contextualizar a RI no paradigma social, o paradigma "socialepistemológico".

Birger Hjørland desenvolveu, junto com Hanne Albrechtsen (Hjørland 2003, 2003a, 2000, 1998, Hjørland/Albrechtsen 1995) um paradigma socialepistemológico chamado „domain analysis“ no qual o estudo de campos cognitivos está em relação direta com comunidades discursivas („discourse communities"), ou seja, com distintos grupos sociais e de trabalho que constituem uma sociedade moderna. Uma consequência prática desse paradigma é o abandono da busca de uma linguagem ideal para representar o conhecimento ou de um algoritmo ideal para modelar a recuperação da informação a que aspiram o paradigma físico e o cognitivo. Uma base de dados bibliográfica ou de textos completos tem caráter eminentemente polissêmico ou, como o poderíamos chamar também, polifônico. Os termos de um léxico não são algo definitivamente fixo.

Com essa explicitação sobre as perspectivas da CC e da CI em relação à RI, tanto como área quanto como processo, ficam visíveis aspectos em comum e distinções na forma de se articular elementos que a CI considera como partes do processo, e que o campo epistemológico da CC não enfatiza com a mesma proporcionalidade da primeira. A relação de objeto da CI com a CC suscita a discussão sobre a objetividade e subjetividade presente em ambas as áreas e fio condutor de amplas discussões filosóficas. É nessa perspectiva que seguiremos na próxima seção, a fim de compreender como tal debate pode proporcionar reflexões para o objetivo do presente estudo. 


\section{A OBJETIVIDADE E A SUBJETIVIDADE NO CONTEXTO DA CIÊNCIA}

A filosofia sempre foi a responsável por questionar elementos que constituem o campo científico, e foi desses questionamentos, enraizados nas mais diversas concepções filosóficas surgidas ao longo de séculos, que se assentou o grande debate sobre a objetividade e a subjetividade no contexto da investigação do fazer científico. A relação objeto-sujeito se fortaleceu, entre as diversas vertentes, por exemplo, tanto pelo idealismo, como pelo realismo.

No que tange a conceitos que servem de base para as várias vertentes - entre elas as citadas acima, e que eventualmente as fundamentaram - podemos citar o objetivismo e o subjetivismo, numa relação, inicialmente, de oposição. No objetivismo, o sujeito é determinado pelo objeto; este se coloca diante da consciência cognoscente do sujeito como coisa pronta, já determinada por suas próprias características. Segundo Johannes Hessen (1999, p. 71), “o centro de gravidade do conhecimento está no objeto.” Um dos primeiros defensores do objetivismo foi Platão. Na concepção platônica, há um reino objetivo, composto de ideias.

É exatamente nesse ponto que reside o pensamento nuclear do objetivismo. Para ele, os objetos são algo dado, apresentando uma estrutura totalmente definida que será, por assim dizer, reconstruída pela consciência cognoscente. (HESSEN, 1999, p. 70).

O objetivismo, presente fortemente na ciência, principalmente como doutrina predominante nas ciências naturais e exatas (química, física, biologia, matemática etc.), foi duramente criticado pela forma de se apreender ao objeto e pela visão de edificação do conhecimento no mundo das ideias. Um dos seus principais críticos foi Edmund Husserl, pai da Fenomenologia.

A crítica de Husserl ao objetivismo da ciência gira, pois, em torno de dois aspectos: a) o esquecimento do sujeito e de seu mundo vital; b) a perda da dimensão ética, pois o método matemático objetivista renuncia explicitamente a tomar posição sobre o mundo do dever-ser. 0 mundo da vida é, para Husserl, um mundo que tem o homem como centro. Por isso, só o retorno à subjetividade transcendental poderá recuperar o sentido do humanismo e superar o desvio objetivista. Ser sujeito transcendental, no entanto, não significa outra coisa que um modo particular de existência do próprio sujeito humano enquanto esse desenvolve, ao máximo, suas possibilidades reflexivas. (ZILLES, 1996, p. 41-42).

O sujeito, na perspectiva objetivista, não era reiterado como parte elementar nas relações de investigação e construção do conhecimento (da ciência). Ao ser concebida a 
existência de um "mundo externo", que independe da relação com o sujeito, a ciência (hard) não considerava como científico o fazer empreendido por outras áreas (soft) do conhecimento, indicando nesse sentido, as ciências sociais. 0 empreendimento de uma visão que propunha o conceber do mundo e todo arcabouço desse processo a partir do sujeito foi batizado de subjetivismo.

[0 subjetivismo] tenta ancorar o conhecimento humano no sujeito. Desloca o mundo das idéias, essa encarnação dos princípios do conhecimento, para o sujeito. 0 sujeito apresenta-se para ele como o ponto no qual a verdade do conhecimento humano está, por assim dizer, suspensa. Não se tem em vista, é claro, o sujeito pensante individual e concreto, mas um sujeito superior, transcendente. (HESSEN, 1999, p. 72).

É a transição do objetivismo para o subjetivismo, concebida por Santo Agostinho (conhecido também por Agostinho de Hipona) - com a ideia de um ser supremo detentor do edifício do conhecimento -, para o que Hessen (1999) chama de neo-kantismo. Por assim dizer, a escola neo-kantista concebeu o subjetivismo partindo do pressuposto lógico. A ideia predominante é de que "Não há objetos independentes da consciência, mas, ao contrário, todos os objetos são produções da consciência, produtos do pensamento." (HESSEN, 1999, p. 73).

Ao se reconhecerem as limitações existentes nas duas doutrinas, em especial nas vertentes que ocorrem em cada doutrina, é possível fazer um exercício de reflexão, por exemplo, da concepção dualista refletida por Baruch Espinoza, importante filósofo holandês, a partir da concepção moneísta/panteísta (HESSEN, 1999) e da influência do positivismo no século XIX, como meio de organização da ciência moderna. É, portanto, entre o polo do objetivismo e o polo do subjetivismo que se manifestaram em diferentes épocas a inscrição tanto de convergências como de divergências sobre a relação objetosujeito. É válido ressaltar que ramos da filosofia, como a Hermenêutica, vislumbram em suas posições a superação dessa relação dual, através do uso da linguagem como forma de compreensão do mundo (STEIN, 2010).

A partir desse entendimento, pode-se incorrer ao exame do que chamamos aqui de subjetividade e objetividade no presente estudo. Recorremo-nos ao dicionário de filosofia, de Nicola Abbagnano (2007). A definição de subjetividade, segundo tal dicionário, refere-se ao "Caráter de todos os fenômenos psíquicos, enquanto fenômenos de consciência (v.), que o sujeito relaciona consigo mesmo e chama de 'meus'" (ABBAGNANO, 2007, p. 922). Já a objetividade é definida, segundo Abbagnano (2007, p. 
721), como "caráter da consideração que procura ver o objeto como ele é, não levando em conta as preferências ou os interesses de quem o considera, mas apenas procedimentos intersubjetivos de averiguação e aferição."

Na concepção das ideias de subjetividade e objetividade elencadas acima, lança-se mão do entendimento de ambas a partir da relação e das influências que estas exerceram nas concepções epistemológicas de áreas do conhecimento. A relação é aqui compreendida não necessariamente sob o objeto de investigação de uma dada ciência, mas nas influências exercidas e expressas em sua visão sobre as múltiplas manifestações de seu objeto, assim como na possível relação do sujeito como partícipe da conjuntura de investigação de processos de uma área científica - entendido aqui como uma das expressões do objeto.

\section{PERCURSO METODOLÓGICO}

A presente pesquisa teve uma abordagem qualitativa, partindo do levantamento bibliográfico. A coleta de dados foi empreendida, inicialmente, no Portal da BRAPCI (2017), responsável por indexar periódicos tanto das áreas de CI como de áreas correlatas, a exemplo da Arquivologia. Entretanto, é válido ressaltar que a revista Acervo, notória publicação de Arquivologia no Brasil, mantida pelo Arquivo Nacional, não é indexada pela BRAPCI. Assim, os procedimentos descritos a seguir foram utilizados tanto no portal da BRAPCI como no portal da revista Acervo.

O primeiro passo, portanto, foi efetuar uma busca (nos portais tanto da BRAPCI como da revista Acervo) utilizando como critérios nos campos de busca o termo composto por "recuperação" associado ao termo "arquivo", que pode indicar tanto termos como "arquivístico" ou "arquivo". Outro critério adotado foi na seleção inicial de quais estudos seriam coletados, onde procurou-se enfatizar estudos que trouxessem como objeto de investigação a RI no contexto da Arquivologia ou de arquivos, com explicitação deste no título ou resumo e com recorte cronológico de 2013 a 2017. Assim, foram recuperados 5 (cinco) estudos no portal da BRAPCI e 1 (um) estudo no portal da revista Acervo, viabilizando uma cobertura do objeto a ser investigado.

O método utilizado para análise dos dados foi a análise de conteúdo, entendida por Bardin (1977, p. 38) como “o conjunto de técnicas de análise das comunicações, que utiliza procedimentos sistemáticos e objetivos de descrição do conteúdo das mensagens." No 
presente estudo, a análise de conteúdo se baseou nos procedimentos trazidos por Campos (2004), que se pauta por processos mais breves e menos densos do que os trazidos por Bardin (1977). Assim, Campos (2004) indica em seu escopo de etapas a possibilidade de definição de categorias (não apriorísticas) após contato inicial com os dados coletados. Na visão do autor, as categorias no contexto da categorização não apriorística

emergem totalmente do contexto das respostas dos sujeitos da pesquisa, o que inicialmente exige do pesquisador um intenso ir e vir ao material analisado e teorias embasadoras, além de não perder de vista o atendimento aos objetivos da pesquisa. (CAMPOS, 2004, p. 614).

Dessa maneira, a aplicação do método de análise de conteúdo teve início com a fase de pré-exploração do material, onde se procurou estabelecer o contexto e deixar-se fluir impressões e orientações (CAMPOS, 2004). Em seguida, foi efetuada a seleção das unidades de análise (ou de unidades de significados). Nessa etapa, vislumbrou-se a análise de temas, em geral contidos ao longo de cada estudo coletado para análise. A razão de se apropriar da análise temática se evidencia pelo objetivo do trabalho de conhecer e discutir as relações entre a objetividade e a subjetividade no contexto da RI no campo arquivístico.

Após contato exaustivo com os dados coletados, foi possível categorizar, baseado na unidade de análise escolhida - temática -, o conteúdo a partir de vertentes que se evidenciavam em torno do assunto investigado - recuperação da informação em arquivos - pelo presente trabalho e, a partir dessas categorias, traçar como cada uma delas foi discutida nos estudos analisados e de que forma contribuem para entendimento do objetivo da pesquisa aqui desenvolvida. É importante frisar também que as unidades de contexto, importantes para se entender com exatidão o sentido da unidade de análise escolhida, se pautaram em parágrafos. Assim, as categorias definidas levavam em conta temáticas que permearam o desenvolvimento do estudo e foram explicitadas como fatores que atuam lado a lado com a RI em arquivos. As categorias foram, portanto: I) Representação da Informação; II) Necessidades de Informação; III) Mediação da Informação; IV) Gestão da Informação; V) Classificação e Organização Documental; VI) Busca, Acesso e Uso da Informação, ilustradas na figura 1: 
Figura 1 - Categorias identificadas a partir dos estudos analisados.

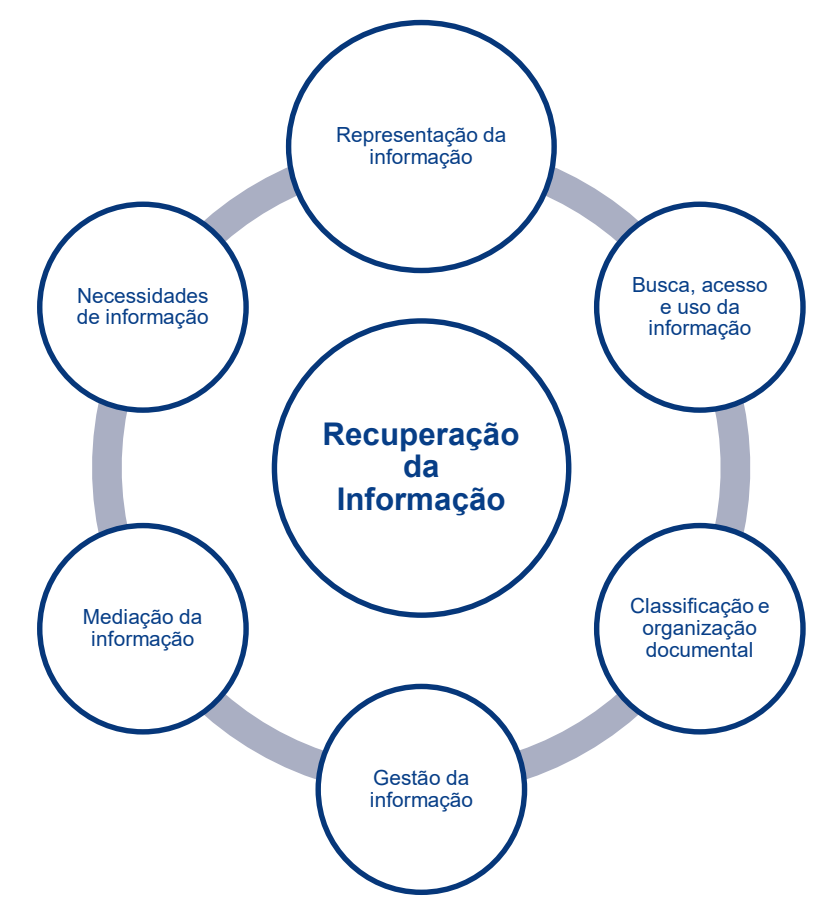

Fonte: Elaborado pelos autores.

Com as categorias definidas, efetivaram-se novas classificações - conforme a fase de codificação do método de análise de conteúdo -, gerando subcategorias onde os estudos coletados se relacionam. Há, obviamente, o intuito de compreender as abordagens específicas dadas nos estudos para cada uma das categorias identificadas. 0 quadro 1, apresentado na próxima seção, exemplifica essas novas classificações.

Portanto, definidas as categorias, conforme a figura 1 (e as subcategorias conforme o quadro 1), foi possível avaliar como outras temáticas puderam se articular com a temática principal do presente trabalho e como tais categorias dialogaram para confluência do tema trabalhado.

\section{A RECUPERAÇÃO DA INFORMAÇÃO EM ARQUIVOS: análise de estudos}

Como já determinado, é necessário conceber e entender a relação da RI em arquivos diante de visões distintas quanto ao foco de investigação, considerando-se as visões da CI e da CC, associadas pelo objeto - a RI. É nesse sentido que se optou por desenvolver a coleta e a análise sobre estudos de RI que se contextualizem no ambiente de arquivos. Assim, foram coletados 6 (seis) estudos, provenientes de revistas e 
periódicos da área arquivística e de CI, indexados, respectivamente, no Portal da BRAPCI (2017) e na revista Acervo. Todos os estudos abrangem o recorte cronológico de 2013 até 2017. Os estudos recuperados e analisados foram:

“Recuperação, acesso e uso dos documentos arquivísticos”, de Johanna Wilhelmina Smit, do ano de 2013;

"A classificação e a taxonomia como instrumentos efetivos para a recuperação da informação arquivística", de Renato Tarciso Barbosa de Sousa e Rogério Henrique de Araújo Júnior, do ano de 2013;

"Recuperação de imagens digitais e normalização arquivística", de Antonio Victor Rodrigues Botão $\boldsymbol{e}$ Rozali Fernandez de Souza, do ano de 2013;

"A indexação na recuperação da informação em arquivos: uma abordagem inicial”, de Mariane Costa Pinto, do ano de 2016;

"Arquivos inteligentes: o uso do hipertexto digital na recuperação da informação", de Carlos Eugênio Silva Neto e Gustavo Henrique de Araújo Freire, do ano de 2013;

"Descrição arquivística: a construção de um sistema de banco de dados para recuperação da informação", de Carlos Alexandre Gomes e Nelma Camêlo Araujo, do ano de 2015.

Desse modo, é necessário expor os dados e determinar os caminhos traçados para coesão do presente estudo, no qual foram determinadas, com a aplicação da análise de conteúdo, categorias e subcategorias (não apriorísticas) no processo de codificação, que dialogam com a recuperação da informação em arquivos.

Quadro 1 - Categorias e subcategorias emergentes da análise de conteúdo.

\begin{tabular}{|c|c|c|}
\hline Categorias & Subcategorias & Estudos \\
\hline \multirow{6}{*}{ Representação da Informação } & Normalização arquivística & $\begin{array}{c}\text { BOTÃO E SOUZA (2013); } \\
\text { GOMES E ARAUJO } \\
(2015) .\end{array}$ \\
\hline & Taxonomia & $\begin{array}{l}\text { SOUSA E ARAÚJO } \\
\text { JUNIOR (2013). }\end{array}$ \\
\hline & Descrição & $\begin{array}{c}\text { SMIT (2013); SOUSA E } \\
\text { ARAÚJO JUNIOR (2013); } \\
\text { GOMES E ARAUJO } \\
\text { (2015); PINTO (2016); } \\
\text { BOTÃO E SOUZA (2013). }\end{array}$ \\
\hline & Indexação & $\begin{array}{l}\text { SMIT (2013); SOUSA E } \\
\text { ARAÚJO JUNIOR (2013); } \\
\text { PINTO (2016); BOTÃO E } \\
\text { SOUZA (2013). }\end{array}$ \\
\hline & NOBRADE & $\begin{array}{c}\text { GOMES E ARAUJO } \\
\text { (2015); BOTÃO E SOUZA } \\
\text { (2013); SILVA NETO E } \\
\text { FREIRE (2013). }\end{array}$ \\
\hline & Hipertexto & $\begin{array}{l}\text { SILVA NETO E FREIRE } \\
\text { (2013). }\end{array}$ \\
\hline Necessidades de informação & Linguagem & $\begin{array}{c}\text { SILVA NETO E FREIRE } \\
\text { (2013). }\end{array}$ \\
\hline
\end{tabular}

Inf. Pauta, Fortaleza, CE, v. 2, n. 2, jul./dez. 2017 


\begin{tabular}{|c|c|c|}
\hline & $\begin{array}{l}\text { Instrumento de RI (Guia, índice, } \\
\text { catálogo etc.) }\end{array}$ & $\begin{array}{c}\text { GOMES E ARAUJO } \\
\text { (2015). }\end{array}$ \\
\hline & Relevância & $\begin{array}{l}\text { SMIT (2013); GOMES E } \\
\text { ARAUJO (2015); BOTÃO } \\
\text { E SOUZA (2013). }\end{array}$ \\
\hline & Tradução em expressões de busca & $\begin{array}{l}\text { SILVA NETO E FREIRE } \\
(2013) .\end{array}$ \\
\hline \multirow{2}{*}{ Mediação de informação } & Acesso & SMIT (2013). \\
\hline & Contexto documental & SMIT (2013). \\
\hline \multirow{2}{*}{ Gestão da informação } & $\begin{array}{l}\text { Produção, análise, organização e } \\
\text { recuperação da informação }\end{array}$ & $\begin{array}{l}\text { SILVA NETO E FREIRE } \\
\text { (2013). }\end{array}$ \\
\hline & Tecnologias digitais & $\begin{array}{l}\text { SILVA NETO E FREIRE } \\
(2013) .\end{array}$ \\
\hline \multirow{4}{*}{$\begin{array}{c}\text { Classificação e organização } \\
\text { documental }\end{array}$} & Parte da função social do arquivista & $\begin{array}{l}\text { SOUSA E ARAÚJO } \\
\text { JUNIOR (2013). }\end{array}$ \\
\hline & Parcialidade/Subjetividade & $\begin{array}{l}\text { SOUSA E ARAÚJO } \\
\text { JUNIOR (2013). }\end{array}$ \\
\hline & Plano de classificação & $\begin{array}{c}\text { SOUSA E ARAÚJO } \\
\text { JUNIOR (2013); SMIT } \\
\text { (2013). }\end{array}$ \\
\hline & Organicidade & SMIT (2013). \\
\hline \multirow{5}{*}{$\begin{array}{l}\text { Busca, acesso e uso da } \\
\text { informação }\end{array}$} & Navegação & $\begin{array}{l}\text { SILVA NETO E FREIRE } \\
(2013) .\end{array}$ \\
\hline & Sistemas de informação & $\begin{array}{l}\text { SILVA NETO E FREIRE } \\
\text { (2013); BOTÃO E SOUZA } \\
\text { (2013). }\end{array}$ \\
\hline & Documentos digitais & $\begin{array}{l}\text { SOUSA E ARAÚJO } \\
\text { JUNIOR (2013). }\end{array}$ \\
\hline & Banco de dados & BOTÃO E SOUZA (2013). \\
\hline & Estratégias de busca & SMIT (2013). \\
\hline
\end{tabular}

Fonte: Elaborado pelos autores.

Os temas identificados na figura 1 - e com mais especificidade no quadro 1 -, aparecem de maneira mais direta em alguns estudos, enquanto em outros aparecem de forma mais discreta. No que toca à temática "representação da informação", praticamente todos os estudos enfatizaram a importância da "representação da informação" como um viés comum no processo e sucesso de RI. Como partícipe desse processo, alguns desses estudos enfatizam o sujeito (SMIT, 2013; SOUSA; ARAÚJO JÚNIOR, 2013; PINTO, 2016; GOMES; ARAÚJO, 2015) - arquivista, indexador - na representação, bem como na posição de usuário, para quem essa mesma representação esteja planejada, coerente e coesa (SMIT, 2013; BOTÃO; SOUSA, 2013; SILVA NETO; FREIRE, 2013; GOMES; ARAÚJO, 2015). É possível, a partir desse primeiro ponto exposto, conceber o lugar do sujeito tanto do lado de quem representa como no lado de quem interpreta a representação.

Quanto aos temas de "busca, acesso e uso da informação", "necessidades de informação" e "mediação da informação", estes aparecem interligados em estudos que concebem um sujeito que visa suprir uma necessidade informacional - relacionada ao 
trabalho, à vida privada (SMIT, 2013; SILVA NETO; FREIRE, 2013), bem como também em relação a um sujeito (arquivista), responsável pelo acesso e mediação da informação (SMIT, 2013; SILVA NETO; FREIRE, 2013). Em um estudo à parte (GOMES; ARAÚJO, 2015), a mediação é apresentada a partir de instrumentos utilizados por um sujeito (arquivista), para disponibilizar informações aos usuários. Outros estudos (SOUSA; ARAÚJO JÚNIOR, 2013) concebem que questões relativas ao tema "busca, acesso e uso da informação", por exemplo, são influenciadas por questões externas ao sujeito que empreende, principalmente, o acesso e a busca. Ainda há os estudos (GOMES; ARAÚJO, 2015) em que o acesso é entendido como um processo, existente em sua própria razão.

A temática referente à "classificação e organização documental" transparece nos estudos sob uma perspectiva tanto de acesso como de preservação de relações entre documentos (SMIT, 2013). Esse vínculo é visto no estudo de Smit (2013) como algo existente ou atributo natural dos conjuntos documentais arquivísticos, ainda que a organização seja empreendida por sujeitos, e os atributos de organicidade sejam julgados a partir das perspectivas destes. A temática de organização é elencada (SMIT, 2013) no objetivo de acesso.

Por último, o tema "gestão da informação" foi citado em alguns estudos de maneira tímida (SOUSA; ARAÚJO JÚNIOR, 2013) e mais expressivamente em outros (SILVA NETO; FREIRE, 2013), na condição de conceito que presume uma cadeia de ações que enfatizem aspectos do acesso, armazenamento e uso da informação por parte de usuários e de pessoas no geral.

É válido enfatizar que, considerando todos esses temas que circundam a recuperação da informação em arquivos, verifica-se uma dispersão no tocante à construção e à exaustividade de tal temática em arquivos. Observa-se que, intuitivamente, ao se abordar a RI em arquivos, presume-se, devido em grande parte à existência de múltiplas variáveis que influenciam a RI no tocante à Arquivologia, a existência de um leque de temas que circundam tal conceito. Temas elencados na figura 1 parecem se postarem como requisitos básicos, ainda que não tragam a mesma intensidade de detalhamento e discussão desses temas nos estudos, onde os focos são variados.

Pelos dados obtidos, verifica-se que as visões baseadas na objetividade e subjetividade investigadas na relação objeto-sujeito não transparecem de maneiras binária, dual, excludente. A lógica dessa relação parece romper com a ideia de não 
integração entre visões advindas do antagonismo entre objeto e sujeito, evidenciando o traçado de "mundo construído" a partir de sujeitos que exercem o seu fazer.

A RI, no presente estudo, mostrou-se como área composta de visões dependentes dos entendimentos da Ciência da Computação, bem como pela Ciência da Informação. Evidenciou-se como um processo constituído por outros e que leva em conta - onde parece haver a influência da CI - a relação com o sujeito, a partir de bases lançadas por outras áreas de interesse.

\section{CONSIDERAÇÕES FINAIS}

Com a exposição dos resultados e sua posterior análise, foi possível se chegar à ideia de RI, no campo arquivístico, detentora de diálogo com outras áreas de investigação que variavelmente dialogam entre si e relacionam a objetividade e subjetividade numa interação pendular. É possível avaliar também, dado o ambiente arquivístico, composto de $n$ variáveis, que a RI aí se estabelece de uma maneira distinta, afinal, a recuperação acaba por se evidenciar tanto do lado do usuário (sujeito), como também do lado do objeto, materializado em ambientes que não estão necessariamente contemplados nas investigações presentes na CC, que relaciona sua atuação à parte computacional, de máquina. Se a RI, em seu aparato do ramo computacional, não estabelece as peculiaridades presentes ao ambiente arquivístico, é tarefa da própria Arquivologia, em pleno diálogo tanto com a CI quanto com a CC, instaurar debates e reflexões sobre o que, anacronicamente, ficou limitado à elaboração de recursos técnicos, como os instrumentos de pesquisa, que são considerados bases para RI na Arquivologia. É nessa ruptura sobre qual RI desejamos para os arquivos - tanto pessoais, como institucionais - que o debate deve se estabelecer, pois é necessário levar em conta que a automatização e o anseio de informação são características de uma sociedade marcada pela exponencial produção de dados, informação e conhecimento. 


\section{REFERÊNCIAS}

ABBAGNANO, Nicola. Dicionário de filosofia. Trad. Alfredo Bosi. 5. ed. São Paulo: Martin Fontes, 2007.

ARAÚJO, Carlos Alberto Ávila. O que é Ciência da Informação? Informação \& Informação, v. 19, n. 1, p. 01-30, dez. 2013. ISSN 1981-8920. Disponível em: <http://www.uel.br/revistas/uel/index.php/informacao/article/view/15958>. Acesso em: 25 jun. 2017.

BAEZA-YATES, Ricardo; RIBEIRO-NETO, Berthier. Recuperação de Informação: Conceitos e Tecnologia das Máquinas de Busca. Bookman Editora, 2013.

BARDIN, Laurence. Análise de Conteúdo. Tradução de Luiz Antero Reto e Augusto Pinheiro. Lisboa: Ed. 70, 1977.

BOTÃO, Antonio Victor Rodrigues; SOUZA, Rosali Fernandez de. Recuperação de imagens digitais e normalização arquivística. Acervo, v. 26, n. 1, p. 93-108, jan./jun. 2013. Disponível em:

<http://revista.arquivonacional.gov.br/index.php/revistaacervo/article/download/493 /492>. Acesso em: 23 jun. 2017.

BRAPCI. Portal da Base de Dados Referenciais de Artigos de Periódicos em Ciência da Informação. 2017. Disponível em: <http://www.brapci.ufpr.br/brapci>. Acesso em: 04 out. 2017.

CAMPOS, Claudinei José Gomes. Método de análise de conteúdo: ferramenta para a análise de dados qualitativos no campo da saúde. Revista brasileira de enfermagem, v. 57, n. 5, 2004. Disponível em: <http://www.scielo.br/pdf/reben/v57n5/a19v57n5.pdf>. Acesso em: 25 jun. 2017.

CAPURRO, Rafael. Epistemologia e Ciência da Informação. In: ENCONTRO NACIONAL DE PESQUISA EM CIÊNCIA DA INFORMAÇÃO, 5., 2003, Belo Horizonte. Anais eletrônicos... Disponível em: <http://www.capurro.de/enancib_p.htm>. Acesso em: 24 jun. 2017.

CARDOSO, Olinda Nogueira Paes. Recuperação de Informação. INFOCOMP Journal of Computer Science, v. 2, n. 1, p. 33-38, nov. 2004. ISSN 1982-3363. Disponível em: <http://www.dcc.ufla.br/infocomp/index.php/INFOCOMP/article/view/46>. Acesso em: 23 jun. 2017.

GARCIA, J. C. R. Recuperação da informação. DataGramaZero, v. 8, n. 6, 2007. Disponível em: <http://www.brapci.ufpr.br/brapci/v/a/10284>. Acesso em: 23 jun. 2017.

GOMES, Carlos Alexandre; ARAÚJO, Nelma Camêlo. Descrição arquivística: a construção de um sistema de banco de dados para recuperação da informação. Archeion Online, v. 3, n. 1, p. 45-64, 2015. Disponível em:

<http://periodicos.ufpb.br/index.php/archeion/article/download/24777/13570>. Acesso em: 22 jun. 2017. 
HESSEN, Johannes. Teoria do conhecimento. Tradução: João Vergílio Gallerani Cuter; revisão técnica: Sérgio Sérvulo da Cunha. São Paulo: Martins Fontes, 1999.

INGWERSEN, Peter Emil Rerup. Information Retrieval Interaction. Taylor Graham, 1992.

KHAPRE, Shailesh; BASHA, MS Saleem. A theoretical paradigm of information retrieval in information science and computer science. International Journal of Computer Science Issues, v. 9, n. 2, p. 1694-0814, 2012. Disponível em: <https://www.ijcsi.org/papers/IJCSI-9-5-2-232-240.pdf>. Acesso em: 24 jun. 2017.

PINTO, Mariane Costa. A indexação na recuperação da informação em arquivos: uma abordagem inicial. ÁGORA, v. 26, n. 52, p. 141-150, 2016. ISSN 0103-3557. Disponível em: <http://oaji.net/articles/2016/2526-1466627505.pdf >. Acesso em: 23 jun. 2017.

POMBO, Olga. Epistemologia da interdisciplinaridade. Ideação, v. 10, n. 1, p. 9-40, 2008. Disponível em: <http://e-

revista.unioeste.br/index.php/ideacao/article/download/4141/3187>. Acesso em: 18 jun. 2017.

SILVA NETO, Carlos Eugênio da; FREIRE, Gustavo Henrique de Araújo. Arquivos inteligentes: o uso do hipertexto digital na recuperação da informação. Biblos: Revista do Instituto de Ciências Humanas e da Informação, v. 27, n. 1, p. 93-106, jan./jun. 2013. Disponível em: <https://www.seer.furg.br/biblos/article/view/2536>. Acesso em: 19 jun. 2017.

SMIT, Johanna Wilhelmina. Recuperação, acesso e uso dos documentos arquivísticos. Ci. Inf., Brasília, DF, v. 42 n. 1, p. 11-23, jan./abr., 2013. Disponível em: <http://revista.ibict.br/ciinf/article/download/1391/1569>. Acesso em: 21 jun. 2017.

SOUSA, Renato Tarciso Barbosa de; ARAÚJO JÚNIOR, Rogério Henrique de. A classificação e a taxonomia como instrumentos efetivos para a recuperação da informação arquivística. Ci. Inf., Brasília, DF, v. 42 n. 1, p. 131-144 jan./abr., 2013. Disponível em: <http://revista.ibict.br/ciinf/article/download/1400/1578>. Acesso em: 22 jun. 2017.

STEIN, Ernildo. Aproximações sobre hermenêutica. 2. ed. Porto Alegre: EDIPUCRS, 2010.

VARELA, Aida Varela; BARBOSA, Marilene Lobo Abreu. Convergências entre a Ciência da Informação e as Ciências Cognitivas. Informação em Pauta, Fortaleza, v. 1, n. 1, p. 4660, jan./jun. 2016.

ZILLES, Urbano. A crise da humanidade européia e a filosofia. Porto Alegre: EDIPUCRS, 1996.

ZINS, Chaim. Redefinindo a ciência da informação: da "ciência da informação" para a "ciência do conhecimento”. Informação \& Sociedade, v. 21, n. 3, 2011. 


\section{SOBRE OS AUTORES}

\section{Dacles Vágner da Silva}

Mestrando do Programa de Pós-Graduação em Ciência da Informação da Universidade Federal do Ceará (UFC). Técnico em Arquivo na Universidade Federal do Ceará (UFC).

E-mail: daclespb@gmail.com

\section{Osvaldo de Souza}

Professor adjunto da Universidade Federal do Ceará (UFC) no Departamento de Ciências da Informação. Doutor em Engenharia de Teleinformática pela Universidade Federal do Ceará (UFC).

E-mail: osvsouza@gmail.com

\section{Jefferson Veras Nunes}

Professor adjunto da Universidade Federal do Ceará (UFC) no Departamento de Ciências da Informação. Doutor em Ciência da Informação pela Universidade Estadual Paulista Júlio de Mesquita Filho (UNESP).

E-mail: jefferson.veras@yahoo.com.br

\section{Lidia Eugenia Cavalcante}

Pós-Doutora em Ciência da Informação pela Université de Montréal - Canadá. Professora associada III do Departamento de Ciências da Informação da Universidade Federal do Ceará (UFC).

E-mail: cavalcantelidiaeugenia@gmail.com

Recebido em: 11/10/2017; Revisado em: 15/12/2017; Aceito em: 23/12/2017.

\section{Como citar este artigo}

SILVA, Dacles Vágner da et al. Entre o objeto e o sujeito: composição, diálogo e confluência na recuperação da informação em arquivos. Informação em Pauta, Fortaleza, v. 2, n. 2, p. 92-109, jul./dez. 2017.

\footnotetext{
i "Information retrieval is concerned with the processes involved in the representation, storage, searching and finding of information which is relevant to a requirement for information desired by a human user". ii "From the definition of the two disciplines of information retrieval it is easy to see that the two disciplines share a common perspective of information retrieval - users, information technology and research directions".

iii "Computer science, information retrieval researchers often treat the information as fact, and use information to do some work, such as an index of information, information coding, decomposition and analysis of information. This view is based on the nature of the information, i.e. specific, definable and can be encoded. Computer Science Information Retrieval follow the rational and traditional principle that information is the factual existence of the external world of things".

iv "in the Field of information science, information retrieval has basically accepted the multilevel nature of the concept of information".
} 